\title{
La espada de agua (Tópicos del romanticismo en García Lorca)
}

Melvin Campos Ocampo ${ }^{1}$, Universidad de Costa Rica

Recibido: 18 de agosto, 2015

Aceptado: 6 octubre, 2015

\section{RESUMEN}

Este artículo analiza el "Poema doble del lago Eden", de Federico García Lorca, para rastrear en el texto diversos tópicos del romanticismo, tomando como punto de partida el libro Los hijos del limo, de Octavio Paz. Se plantea que el texto está estructurado en cuatro tiempos: un pasado idílico perdido, un presente moderno trágico, un futuro donde se desea retornar al pasado y un presente en el que se ha vuelto al pasado idílico. Además, se asocia ambiguamente el agua con la vida y la muerte y se culpa tácitamente a Dios de haber perdido el pasado idílico.

\section{ABSTRACT}

\section{LA ESPADA DE AGUA (The Water Sword) (TOPICS OF ROMATICISM IN GARCÍA LORCA)}

This paper analyzes the "Poema doble del lago Eden" (Double Poem of the Lake of Eden), by Federico García Lorca, in order to trace along the text diverse topics of romanticism taking as a point of departure Los hijos del limo, by Octavio Paz. It is hypothesized that the text is structured in four tenses; a lost idyllic past, a modern tragic present, a future which wishes to return to the past, and a present which revives the idyllic past. Besides, there is an ambiguous association between water and life and death, and God is tacitly blamed for having lost the idyllic past.

$1 \quad$ Melvin Campos es profesor de la Cátedra de Humanidades de la Universidad de Costa Rica y Vicepresidente del comité costarricense del Consejo Internacional de Monumentos y Sitios Históricos, ICOMOS. Es licenciado en Filología Española, graduado de la Universidad de Costa Rica. Contacto: melvin.campos@ucr.ac.cr.

PALABRAS CLAVE:

Poesía española, romanticismo, Generación del 27, Federico García Lorca, Octavio Paz, paraíso perdido, muerte, infancia.

KEY WORDS:

Spanish poetry, romanticism, Generation of the 27, Federico García Lorca, Octavio Paz, lost paradise, death, childhood. 
Después de haber sacado al hombre, puso al oriente del jardín unos seres alados y una espada ardiendo que daba vueltas hacia todos lados, para evitar que nadie llegara al árbol de la vida.

Génesis. Capítulo 3: Versículo 24, Reina Valera de 1960.

\section{PREÁMBULO EDÉNICO (ANTES DE VIAJAR AL PARAÍSO)}

Sugería Borges que la historia humana y aun la literatura son, quizá, solamente la diversa entonación de unas cuantas metáforas. Si compartiéramos el punto de vista borgesiano, forzosamente deberíamos aceptar que la originalidad no existe. Todo lo que ha dicho la humanidad, desde Pitágoras hasta Nerval, desde Hesíodo hasta Gracián, desde Cervantes hasta Dante, son variaciones (en el sentido musical, inclusive) sobre cinco o seis temas. Ello nos permitiría encontrar hilos temáticos que unan todos los textos. Seríamos capaces de rastrear las líneas que nos llevan directamente desde Homero hasta Carlos Fuentes. Peor aún: esta idea —que, sin duda, subyace en el concepto de intertextualidad y posibilita la literatura comparada - implicaría que ni siquiera ella es original.

En un mundo aún dominado por la concepción romántica del artista creador — semidivino- la angustia de artistas y estudiosos sería una consecuencia lógica. No creo, sin embargo, que deba ser así. Por el contrario, es fascinante que-como afirmaba Aglié en El péndulo de Foucault- todo en el universo esté relacionado de alguna forma, unas veces obvia y otras, críptica.

Aún esta es una idea romántica repetida: el texto del cosmos, el orden relacional del universo. Pero, dado que la cultura es el eterno intento humano de encontrar ese orden en la naturaleza, entonces el primer sumerio en buscar relaciones entre las estrellas para bautizarlas - Toro, Pez, Carnero- estaba incurriendo en una actitud romántica. Y el romanticismo, también formaría parte de ese sobrecogedor (¿monstruoso?) entramado universal.

Desde esta perspectiva, encontrar en cualquier texto temas románticos no es descabellado. Si esos pocos tópicos recorren la historia de la literatura, podríamos afirmar que puede haber romanticismo en Longo o carnavalización en Aristófanes.

Este artículo surge como producto de una investigación realizada en el marco de la maestría en Literatura Latinoamericana de la Universidad de Costa Rica, y tiene por norte la búsqueda en el "Poema doble del lago Eden", del gran Federico García Lorca (1992, pp. 165-167), cuál es esa herencia del Romanticismo. Y, como el universo tiene su orden, así también mi indagación. Primero, analizaré algunos aspectos formales; luego, pretendo estudiar el carácter trágico del fluir temporal para el ser humano; en tercer lugar, voy a referirme la simbología del agua en relación con dicha tragedia; y, por último, revelaré quién es el culpable de esta trágica condición humana.

\section{EL PODER DEL VERSO}

Para los románticos, existe una relación entre todos los elementos del universo, una sintaxis cósmica que permite comprender el universo como un poema. Es lo que Octavio Paz denomina analogía (Paz, 1985, p. 58). Desde esa perspectiva, estamos en capacidad — o tal vez, inclusive, en la obligación — de realizar un análisis lo más detallado posible, pues todo en el poema juega un papel clave en la organización microcósmica del texto.

Con esto en mente, abordemos los aspectos formales del "Poema doble del lago Edén". En primera instancia, el poema está construido con una rima asonante la cual, aunque no sigue un patrón exacto, tiende a ser regular en los versos impares $(7,9,11$, 13, 19, 21, 23, 25, 27, 29, 31, 33, 35, 37, 39, 41, 43,47 y 49). Los únicos versos pares que Ilevan rima son el 2, el 4, el 16 y el 46. La rima utiliza las vocales fuertes ' $a$ ' $y$ ' $\mathrm{O}$ '. Esta rima mantiene la sonoridad en tonos bajos, lo cual produce en el poema una gravedad casi funeraria, semejante a la que se puede encontrar en los cantos gregorianos.

Por otro lado, la métrica del poema es libre y va desde los heptasílabos hasta algunos versos con veinte sílabas. El metro quebrado produce una irregularidad en el poema, una variación que deriva en que el lector enfrente un sentimiento de inestabilidad. 
Ambos rasgos coinciden con el sentido del poema: como veremos, se trata de un universo de confusión, desordenado, caótico, trágico, que el hablante lírico presencia en la condición humana. Pasemos, ahora, a analizar el texto propiamente, a la luz del romanticismo.

\section{LA MALDICIÓN DE HERÁCLITO (TRAGEDIA HUMANA EN CUATRO ACTOS)}

Los tiempos verbales utilizados en el poema, dan la clave para discernir que está estructurado en dos macrosecuencias. La primera, que abarca del verso 1 al 43, está marcada por tres tiempos: un pasado perdido, un presente repudiado y un futuro deseado. La segunda macrosecuencia va del verso 44 al 49 y trastoca la lógica temporal que el poema había establecido anteriormente.

He optado por no sucumbir a la tentación lógica de ordenar mi análisis de acuerdo con los tiempos pasado, presente y futuro. Esto porque, en tanto existe una coincidencia entre el pasado y el futuro deseado, considero más claro estudiar primero el presente y, luego, ver ese pasado/futuro.

Adelantaré, para facilitar la comprensión, que el poema se estructura en cuatro tiempos: un pasado perdido, un presente trágico, un futuro anhelado (donde se desea retornar al pasado) y un presente no trágico (pues se ha vuelto a un estado como el pretérito).

\subsection{El presente doloroso}

Ahora bien, para iniciar nuestra comprobación, veamos que los verbos en presente ubican al lector en un tiempo actual. Este "ahora" está caracterizado por una serie de significantes que lo marcan como un tiempo de dolor y tragedia, de angustia y Ilanto.

Estás aquí bebiendo mi sangre, bebiendo mi humor de niño pasado, mientras mis ojos se quiebran en el viento con el aluminio y las voces de los borrachos (vv. 10-13).

Así, el presente es un tiempo donde el Yo Lírico ve su vida ("sangre") ser absorbida por un Tú Lírico (más adelante nos detendremos en él): es víctima de una suerte de vampiro que lo destruye, lo asesina. Este sufrimiento producido en el presente provoca llanto ("mis ojos se quiebran en el viento") y está vinculado con lo metálico ("aluminio").

Esta primera aparición del elemento metálico revela el inicio de una constante en el poema. Y es que el "ahora" se vincula con significantes como el mencionado "aluminio", con "un viejo alfiler oxidado" (v. 21), se trata de un tiempo de lo concreto (v. 23), de un mundo de "hojalata" (v. 31) donde gobiernan "los trenes" (v. 45). Así, esta relación del presente con lo metálico lo marca como un tiempo de la modernidad, donde los avances humanos (trenes, alfiler) son despreciados (pues se los califica de "hojalata") y están en decadencia, manchados de óxido.

Yo sé el uso más secreto

que tiene un viejo alfiler oxidado

y sé del horror de unos ojos despiertos

sobre la superficie concreta del plato (vv. 20-

23).

Así, este presente se encuentra revestido de angustia, dolor y tragedia por lo concreto. Y, como vimos, es el universo de la modernidad, gobernado por el metal, donde domina el capital y el valor del ser humano es secundario, pues sólo existe en tanto pueda producir riqueza.

Apuntaba Octavio Paz en Los hijos del limo que, si bien el romanticismo es un hijo inexorable de la modernidad, también es su más vehemente y apasionado detractor (Paz, 1985, p. 33). Uno de los principales aspectos criticado por el romanticismo a la modernidad es que la sociedad moderna está fundada en la desigualdad, en tanto es la Era del Capitalismo (Paz, 1985, p. 36): para que alguien sea rico, forzosamente debe obtener su capital arrebatándolo de las manos de otro. En ese sentido, el hambre es un producto de la modernidad - no exclusivo, tal vez; pero sí ineludiblemente vinculado a ella-y el romanticismo se opone abiertamente a esto.

Es, ahora, comprensible el horror que se produce en los "ojos despiertos" (lúcidos, conscientes) al presenciar la trágica "superficie concreta del plato": el plato está vacío y, sin alimento, hay hambre y muerte. Este es el mundo de la locura, la destrucción y la angustia: 
Esos perros marinos se persiguen

y el viento acecha troncos descuidados.

¡Oh voz antigua, quema con tu lengua

esta voz de hojalata y de talco! (vv. 28-31).

Según Jean Chevalier (1999, p. 816), el perro entre otros rasgos - es símbolo fundamental de la muerte, es psicopompo y guardián del inframundo. Su presencia marca este tiempo con la muerte: es el momento en que la naturaleza está enloquecida (perros que se persiguen) y destruida ("troncos descuidados"), es cuando habla la "voz de hojalata". El adjetivo demostrativo "esta" vincula la voz con el presente, la acerca al Hablante Lírico. El sustantivo en aposición "hojalata" marca el carácter despectivo que esta modernidad reviste en el poema.

Este presente de dolor es, a la vez, un tiempo que niega la identidad:

Quiero llorar [...]

porque no soy un hombre, ni un poeta, ni una

hoja,

pero sí un pulso herido que ronda las cosas del otro lado. (vv. 32, 34-35).

Cuando el hablante lírico niega su carácter de ser humano y de poeta, características fundamentales para la autodefinición del sujeto escritor, muestra que el "ahora" le impide cualquier tipo de identidad. Si interpretamos la hoja como sinécdoque del trabajo de escritura, podemos ver que el presente niega hasta la posibilidad de acercarse a dicha labor. Aún peor, lo único que ofrece un rasgo identitario al hablante lírico es el dolor, la herida (v. 35), la cercanía "del otro lado". Este "otro lado", como veremos más adelante, es la muerte. Se trata, entonces, de un tiempo limítrofe con la muerte.

En el laberinto de biombos es mi desnudo el que recibe

la luna de castigo y el reloj encenizado. (vv. 42-43).

De modo que es un tiempo de confusión y dificultad ("el laberinto"), donde el hablante lírico se encuentra en un estado de total fragilidad ("mi desnudo").
La presencia del "biombo" y de "la luna de castigo" remite a una clásica imagen del romanticismo: la imposibilidad del conocimiento - en tanto siempre hay un velo que oculta la realidad de las cosas-y el engaño en que vive en el ser humano - la luna como luz falsa, mentirosa-.

La imagen "el reloj encenizado" es particularmente aclaratoria de este presente: por un lado, el avance del reloj es inexorable, no discrimina a nadie; por otro, el color gris de la ceniza remite por metonimia a las canas, a la vejez, a la decadencia humana. Así, el reloj encenizado es el tiempo humano, finito, mortal, metrónomo cruel que, con cada golpe de su ritmo, recuerda la cercanía del ineludible destino humano.

Así, el hablante lírico vive en el presente, un tiempo de confusión, fragilidad, engaño y tiempo inexorable que lleva sin escapatoria a la decadencia y a la muerte.

\subsection{El pasado idílico}

Pero no siempre se ha sufrido de esta manera. Analizaremos ahora un pasado diferente, pues hubo una época en que:

Era mi voz antigua

ignorante de los densos jugos amargos (vv. 1-2).

Los dos primeros versos dan la clave de lectura del poema: en un tiempo anterior, ya pasado, se desconocía el sufrimiento - "los densos jugos amargos" que provoca el presente. Este pasado se reconoce por los verbos en pretérito imperfecto (era, manaban, conocía) y la recurrencia del adjetivo "antigua" — más adelante hablaremos del carácter antiguo de esta vOz-. En efecto, este tiempo anterior se ha perdido:

¡Ay voz antigua de mi amor!

¡Ay voz de mi verdad!

¡Ay voz de mi abierto costado,

cuando todas las rosas manaban de mi lengua

y el césped no conocía la impasible dentadura del caballo! (vv. 5-9).

El tiempo perdido está marcado por significantes como "amor" y "verdad" (el "abierto costado", lo mencionaremos luego), relaciones que lo caracterizan como una época ideal, cuando se vivía en paz y sin engaño. Era un tiempo de poesía hermosa y 
vinculada con lo floral ("cuando todas las rosas manaban de mi lengua") y cuando no existía decadencia y la naturaleza era inmaculada ("el césped no conocía la impasible dentadura del caballo").

Este tiempo perfecto, esta Edad de Oro, está vinculada con lo infantil: "mi humor de niño pasado" (v. 11). La calificación del "niño" con el adjetivo "pasado" lo relaciona directamente con aquello perdido, con el tiempo que se extraña. De modo que, en el poema, se da una añoranza del pasado, de la inocencia anterior, de la infancia, de ese tiempo idíli$\mathrm{CO}$, dorado, que se ha perdido al igual que el Edén (Génesis, 3: 24, Biblia Reina Valera, 1960). El propio título del poema nos ubica en la tradición del paraíso perdido: Poema doble del lago Edén. En su momento tocaremos el punto del lago y de la dualidad.

\subsection{El anhelo de un futuro idílico}

Arribamos, ahora, al punto clave de este poema: se da en el texto una contraposición entre el presente doloroso y un pasado idílico, al cual se desea regresar en el futuro. En efecto, el anhelo para el futuro está marcado por verbos en imperativo (dejarme) o de deseo: ("quiero", "deseo"), que demandan volver a esa edad dorada de inocencia, sin dolor ni mácula alguna: el Edén perdido.

Dejarme pasar la puerta donde Eva come hormigas y Adán fecunda peces deslumbrados.

Dejarme pasar, hombrecillo de los cuernos, al bosque de los desperezos

y los alegrísimos saltos (vv. 14-19),

El hablante lírico se sitúa ante una puerta (v. 14), en un umbral que es preludio de una crisis, de un cambio radical (Bajtín, 1989, p. 399). Se desea cruzar dicho umbral para regresar a ese paraíso perdido que es primitivo ("donde Eva come hormigas") y, a la vez, fecundo y vital ("Adán fecunda peces deslumbrados"). Esta idea se ve reforzada gracias a que el pez es símbolo de vida y fecundidad (Chevalier, 1999, p. 824). Así, en otro tópico recurrente en el romanticismo, se anhela la vuelta a ese edénico lugar donde no hay complicaciones ("bosque de los desperezos") y todo es felicidad ("los alegrísimos saltos").
Afirmaba Octavio Paz que la caída de Adán significa la ruptura del paradisíaco presente eterno (tiempo mítico), para caer en el tiempo moderno y, cuando comienza la sucesión de las diferencias, comienza la escisión y, con ellos, el distanciamiento entre el ser humano y el paraíso (Paz, 1985, p. 20). De modo que el deseo de volver con Adán y Eva significa, evidentemente, el retorno al Edén pero, más allá de este simplismo, es el anhelo de retornar a un tiempo de la igualdad, donde todo es siempre idéntico a sí mismo, donde el devenir del tiempo — contrario a Heráclito- - no implica el envejecimiento ni la degradación de lo vivo.

Pero no quiero mundo ni sueño, voz divina, quiero mi libertad, mi amor humano en el rincón más oscuro de la brisa que nadie quiera.

¡Mi amor humano! (vv. 24-27).

Si interpretamos el sueño en el sentido romántico, como falsedad ilusoria (Bécquer, 2003, p. 288), podemos comprender el verso 24 como un rechazo a la mentira, al "sueño" que engaña en el presente. El rechazo al mundo está relacionado con la obligatoria decadencia, mutación, que sucede en el mundo real. Al oponerse este mundo a ese tiempo deseado de libertad y amor (v. 25), por inferencia se deduce que el mundo es el lugar del odio y los límites, de las represiones que restringen al ser humano. Se desea ese tiempo que no es engañoso ni decadente, que está pleno de amor hasta "en el rincón más oscuro". Así, el anhelo del mundo pasado proyecta al hablante lírico a un mundo de voluntad irrestricta, de libertad infantil e inocente:

Quiero llorar porque me da la gana, como lloran los niños del último banco... (vv. 32-33).

Quiero llorar diciendo mi nombre, rosa, niño y abeto a la orilla de este lago, para decir mi verdad de hombre de sangre matando en mí la burla y la sugestión del vocablo (vv. 36-39).

Se trata de un tiempo de llanto voluntario, dulce e infantil, no forzoso y trágico como el producido por el dolor, el hambre y la angustia del presente. Es un momento de autorreconocimiento, de identidad 
("diciendo mi nombre"), de vínculo con la naturaleza ("rosa", "abeto", "lago"), de inocencia primordial ("niño"), de "verdad" humana ("hombre de sangre"). Es un tiempo donde no existen "burla" ni engaño ("la sugestión del vocablo"), aspectos del mundo repudiados por el romanticismo.

De manera que el deseo que se da en el presente, hacia el futuro, coincide con el pasado; en otras palabras, el hablante lírico ahora desea que en el futuro regrese el pasado. Ahora bien, este deseo de retorno a lo natural, a la inocencia primordial, se busca como alternativa ante ese presente marcado por la modernidad que, como vimos anteriormente, es rechazada por el poema.

En relación con esta idea, Octavio Paz resulta un punto de apoyo fundamental.

... la exaltación de la naturaleza es tanto una crítica moral y política a la civilización como la afirmación de un tiempo anterior a la historia [...] el primer principio, el fundamento de la sociedad, no es el cambio ni el tiempo sucesivo de la historia, sino un tiempo anterior, igual a sí mismo siempre (Paz, 1985, p. 18).

Este pasado idílico se opone al tiempo histórico que implica cambio, mutación y, por ende, decadencia pues, en aquellos dorados tiempos, el ser humano no envejecía ni conocía dolor. El tiempo sucesivo del cambio moderno implica necesariamente una ruptura con el tiempo recurrente del mito, el tiempo de la identidad. Este tiempo del cambio implica el envejecimiento y la decadencia de las cosas. Por tal razón, rechazar la modernidad, implica también un repudio a su tiempo del cambio, con miras a anular el cambio, a eliminar la vejez humana y se busca "el tiempo del principio en el futuro" (Paz, 1985, p. 37).

El hablante lírico es coherente con esta idea pues, para él, el tiempo del presente moderno implica la decadencia ("reloj encenizado"). La modernidad es un "continuo ir hacia allá, siempre allá —no sabemos dónde. Y llamamos a esto progreso" (Paz, 1985, p. 30) y de esta concepción de tiempo reniega el poema: del cambio en el tiempo moderno, de la historia, siempre mutable, siempre distinta. El texto, en la tradición romántica de la ruptura, por oposición a la modernidad, busca anular ese tiempo de la diferencia y regresar al momento de la identidad idílica.

Es por ello que asocia al futuro/pasado la frase "diciendo mi nombre" (v. 36): en ella el hablante lírico se identifica, se autodefine. La identidad, afirma Paz, es hija del tiempo cíclico - $-y$, por consiguiente, también la analogía, en tanto principio de identidad(Paz, 1985, p. 67). Esto implica que la identidad es del orden del mito, la imagen de unicidad es mítica.

\subsection{Ambigüedad entre la completud y la muerte}

Sin embargo, Paz anota un hecho importante: detener el tiempo es la muerte (Paz, 1985, p. 26). De modo que, si bien este tiempo de oro, es anhelado por perfecto, inocente, idílico e indiferenciado, también es, a la vez, trágico, peligroso, mortal. Y el poema también reviste al paraíso de este carácter.

En efecto, la primera vez que el hablante lírico se refiere a la "vOz antigua", la asocia con el dolor crístico del "abierto costado" (v. 7). Además, cuando manifiesta el deseo de regreso al pasado, sabe que es un tiempo de Ilanto - "Quiero llorar porque me da la gana" (v. 32)_; voluntario, es cierto, pero llanto al fin y al cabo. Por otra parte, cuando desea regresar al lugar paradisíaco, lo define como el espacio "donde Eva come hormigas".

La presencia de la hormiga como símbolo es recurrente en tres de los pilares del surrealismo español: Dalí, Buñuel y García Lorca. Para Chevalier, la hormiga es símbolo de la vida industriosa, organizada en sociedad, pero también el apego excesivo a los bienes materiales (Chevalier, 1999, p. 577). Particularmente, Buñuel utiliza esta imagen con este sentido. En Un perro andaluz, por ejemplo, la muchacha protagonista ve al joven ciclista que examina su mano izquierda con espanto $y$, al pasar a un plano detalle de la mano, se observa que en la palma pululan hormigas (Buñuel, 1971, p. 33). Esto funciona en Buñuel como una metáfora del ser humano exorcizado del monstruoso régimen de la eficiencia moderna.

Sin embargo, en el caso del poema que nos ocupa, el símbolo de la hormiga coincide con la tragedia destructiva de este tiempo anterior. Así, el poema marca ese anhelo de vuelta al pasado con significantes referidos a lo doloroso. Esta idea coincide con la 
visión romántica de la conjunción con la Edad de Oro: se desea regresar al pasado mejor, aunque se sabe que ello derivaría en la muerte. Es lo que hemos dado en llamar la conjunción disfórica: una vinculación entre dos elementos que deriva en la anulación de uno de los dos elementos.

Así, el Edén tiene un carácter doble: uno añorado y uno trágico. Este rasgo dual se puede explicar partiendo del psicoanálisis. Para el saber iniciado por Freud, esta Edad de Oro, de perfección y completud, es una metáfora del vientre materno como lugar de totalidad: en él se es uno con la madre, no se carece de nada, no falta nada. La madre es el objeto primordial, perdido al ingresar en la cultura (Baudes de Moresco, 1995, p. 63). La falta de este objeto es el hecho que funda el deseo y, con él, la vida psíquica. Por consiguiente, si se recuperase el objeto —el vientre materno-, se frenaría el deseo y sobrevendría la muerte psíquica. Así, se desea al vientre materno pero, a la vez, se sabe que su presencia produciría la muerte. Este fenómeno es lo que Freud denomina pulsión de muerte (Freud, 1998, p. 42). Desde esta perspectiva, es comprensible que el retorno al tiempo idílico sea anhelado y temido a la vez.

La mencionada búsqueda de la identidad concuerda con el tiempo cíclico del mito, de la Edad de Oro, en oposición al tiempo sucesivo de la modernidad. Éste se halla relacionado con el eterno retorno, con la identidad temporal de los momentos. Decía Paz que el romanticismo busca un retorno al tiempo idéntico, primordial, para anular el tiempo de la diferencia y el cambio (Paz, 1985, p. 37). En este sentido, apunta el psicoanalista argentino Néstor Braunstein que la idea del eterno retorno, del tiempo cíclico, es del orden de lo real (1993, p. 40) y, por consiguiente, es deseado y repudiado, a la vez.

Ahora es más claro el carácter programático del título: "Poema doble del lago Edén". Se trata de un poema sobre el Edén, el paraíso perdido, pero es un texto doble: el paraíso se añora y se repudia. En la mejor tradición de Catulo, se odia y se ama al Edén, al paraíso, a la Edad de Oro de completitud e indiferenciación humanas.

\subsection{El tiempo detenido de la muerte}

Pues bien, hemos analizado los tiempos que estructuran el poema y su relación con el paraíso perdido y con la Edad de Oro. Veamos, ahora, qué acontece en la segunda macrosecuencia.

Así hablaba yo.

Así hablaba yo cuando Saturno detuvo los trenes y la bruma y el sueño y la muerte me estaban buscando.

Me estaban buscando

allí donde mugen las vacas que tienen patitas de paje y allí donde flota mi cuerpo entre los equilibrios contrarios (vv. 44-49).

La estrofa inicia marcando un distanciamiento con el resto del poema: todo lo dicho anteriormente se decía en un tiempo anterior ("Así hablaba yo"). Esto implica que en el presente, en este nuevo presente, distinto de la primera macrosecuencia del poema, se habla de otra forma. Este tiempo ahora tiene un matiz distinto al que se le asignó en la primera sección.

En efecto, se trata de un presente alterado: el presente trágico de la primera macrosecuencia se ha dejado atrás. El tiempo de dolor es anterior al segundo presente. Por la presencia de los verbos en pretérito imperfecto, sabemos que el dolor y la tragedia ya no son presentes, sino pasados. Algo ha sucedido que modificó al hablante lírico.

El cambio se marca por un punto en el tiempo: "cuando" (v. 45). Los hechos que suceden en ese instante son las causas de la transformación en el hablante lírico. Pero, ¿qué ha sucedido? En primera instancia, "Saturno detuvo los trenes". En Roma, Saturno es el nombre que se otorga al Cronos griego: el tiempo. Lo que tenemos, entonces, es el tiempo detenido. Y si interpretamos los "trenes" como sinécdoque del tiempo moderno, comprendemos que el tiempo moderno de la mutación y el cambio se han detenido. Ha llegado el tiempo idéntico, de la igualdad. Se ha regresado al tiempo idílico/idéntico de la Edad de Oro.

El tiempo primordial modelo de todos los tiempos, la era de la concordia entre el hombre y la naturaleza y entre el hombre y los hombres, se llama en Occidente la edad de oro. [...] la 
ambigüedad del tiempo cíclico: el arquetipo temporal está en el tiempo y adopta la forma de un pasado que regresa [...] la edad dichosa es un tiempo de acuerdo, una conjunción de los tiempos... (Paz, 1985, p. 18).

Desde esta perspectiva, para el pensamiento mítico, el tiempo no es portador del cambio, sino que es el agente que lo suprime. Se trata de la igualdad, el tiempo de la muerte, un más allá en el que el tiempo reposa inmutable, idéntico (Paz, 1985, p. 16).

Ese tiempo moderno anterior, era cuando "la bruma y el sueño y la muerte me estaban buscando.", o sea, el tiempo cuando la ilusión, el engaño y la muerte, perseguían al hablante lírico: el tiempo de lo humano. Ahora bien, el tratar esta persecución de que es objeto todo ser humano, como un pretérito, implica que estos elementos ya no lo buscan. El verso 45 nos permite entender que no lo buscan porque lo encontraron. Se ha superado el tiempo del cambio, el envejecimiento y la decadencia; llegó ese futuro anhelado donde nada se destruye: la muerte.

La imagen "las vacas que tienen patitas de paje", por causa del diminutivo "patitas", sugiere una metáfora de la fragilidad: unos endebles soportes para un animal grande y pesado. Se trata de la debilidad del tiempo pasado, del mundo material que lleva inexorablemente a la decadencia, cuando el hablante lírico era acechado por la muerte y el engaño. Así termina el tiempo de lo humano, cuando el ser humano era frágil y mortal.

El verso 49 expone el lugar momento de la muerte. La acción de flotar —acción pasiva por cierto—, no sucede en el aire, sino en el agua, en el lago. Nótese que el hablante lírico se refiere al cuerpo como un objeto separado de él: no floto yo, sino mi cuerpo. Esto implica que el cuerpo ya no está con el Yo, son entidades distintas. Y el único momento en que el yo se puede separar del cuerpo es en la muerte.

Así, el cuerpo del Yo flota en el lago mientras el hablante lírico se encuentra disociado de todas las tragedias que implicaba el tiempo sucesivo. Se encuentra, entonces, en el espacio del tiempo idéntico, inmutable, ese lugar donde, según el poema náhuatl citado por Octavio Paz, "el agua del mar se junta con la del cielo" (Paz, 1985, p. 18). Ése es el final del tiempo.
Por otra parte, en tanto el cuerpo del Yo flota "entre los equilibrios contrarios", se ubica en el lugar donde toda diferencia se anula. Y la anulación de los contrarios es una tentativa por anular los cambios, por detener el río de Heráclito (Paz, 1985, p. 21). Ése es el objetivo del principio de identidad del tiempo mítico: suprimir las contradicciones, frenar la tragedia humana (Paz, 1985, p. 27). El cuerpo es el espacio donde todo se funde en un solo universo de la identidad, la unión del todo con el todo: la paz, sí; pero también la muerte. El cuerpo es, entonces, el lugar donde acontece la conjunción disfórica. Se ha regresado a la Edad de Oro.

Ahora podemos analizar con mayor claridad el epígrafe del poema. Tomado de la Égloga II, de Garcilaso (v. 1146), la frase reza: "Nuestro ganado pace, el viento espira" (2004, p. 302). El episodio retrata una conversación entre Salicio y Nemoroso; la frase es dicha por el primero al segundo. Se trata de un momento de paz, descanso y tranquilidad. Es clara la referencia al Épodo II, de Horacio, el beatus ille, en tanto se trata de una escena bucólica, muestra un Edén dorado. Lo interesante del caso es que los verbos pacer y espirar están en presente, tiempo asociado, entonces, con lo idílico. Por tal razón, el epígrafe establece una coincidencia con la estrofa final del poema, cuando el presente es un tiempo de inocencia y paz, en contraposición con el tiempo de tragedia que se ha dejado atrás. Es el tiempo sin cambio, siempre estático. Así, se da la conjunción disfórica, anhelada y temida, se llega a un tiempo de la identidad, donde los contrarios no existen.

Como hemos visto, la estructura del poema se hace en cuatro tiempos: pasado perdido, presente trágico, futuro anhelado (retorno del pasado) y presente alterado (llegada del pasado). En cada tiempo aparecen mencionados elementos — rasgos, adjetivos, sustantivos - relacionados con lo metálico y con lo líquido. Pero, ¿cómo se relacionan dichos elementos en este juego de lágrimas?

\section{EL LAGO SIN ESPERANZA (AGUA ERES Y AL AGUA VOLVERÁS...)}

La sección del Poeta en Nueva York a la que pertenece nuestro poema lleva por nombre "Poemas del lago Eden Mills" e inaugura el distanciamiento de la ciudad y lo moderno, tratando de regresar a un 
ambiente bucólico, edénico. Por su parte, el hecho de que el título del poema se refiera el lago Edén, establece una unión entre lo acuático y el Edén, el paraíso perdido. Ya hemos analizado lo referido al paraíso, ahora revisemos el carácter que el poema le otorga a lo acuático.

Propiamente en el poema, es notable una oposición entre lo líquido y lo sólido, donde cada uno se relaciona, respectivamente, con el "antes" y el Edén perdido (lago Edén) y con el "ahora" de la modernidad metálica repudiada. En efecto, el poema no trabaja sólo con el agua, sino todo líquido, opuesto a lo sólido, concreto y metálico.

Como mencionamos en el apartado anterior, el "ahora" se vincula con significantes como "aluminio", "viejo alfiler oxidado", "concreta", "hojalata" $y$ "los trenes". Esto marca el presente como un tiempo moderno de dureza y solidez metálicas. Por su parte, lo líquido se relaciona con significantes como fragilidad ("los frágiles helechos mojados", v. 4), palabras dulces, suaves y puras ("cuando todas las rosas manaban de mi lengua", v. 8), pureza, infancia e inocencia perdidas ("humor de niño pasado", v. 11). Esto refuerza la relación de lo líquido con ese paraíso perdido y añorado.

Otro elemento líquido que se ofrece es el Ilanto, siempre relacionado con lo infantil (vv. 33, 36-37), con el tiempo pasado, primordial, inocente y paradisíaco. Recordemos los versos citados anteriormente:

Quiero llorar porque me da la gana, como lloran los niños del último banco, porque no soy un hombre, ni un poeta, ni una hoja,

pero sí un pulso herido que ronda las cosas del otro lado (vv. 32-35).

El Ilanto vincula al ser humano con el agua: es el flujo acuático de los ojos y, en este caso particular, el llanto es un instrumento de autodefinición, de afirmación de la voluntad ("Ilorar porque me da la gana"). Se desea el llanto como símbolo de lo primordial, el regreso a lo acuático como medio para retornar a la inocencia primitiva, infantil.

Por otra parte, la causa del Ilanto (el "porque" del verso 34), vinculada con el presente, es el no ser, la falta de esencia humana en el Hablante Lírico (ni hombre ni poeta). Por ello, podemos deducir que en el presente se produce una falta de identidad, una diferencia, en el "ahora" moderno no existe lo idéntico, sólo lo distinto.

Notemos, además, que el único rasgo que define al yo es el dolor ("pulso herido"), el acercamiento a algo (rondar), que se encuentra al otro lado de algo indefinido. Planteo que eso indefinido es el lago. Esta idea se ve reforzada con las deducciones realizadas hasta el momento: ellas nos permiten interpretar ese "otro lado" como el lado de la Edad de Oro, ese lugar que no es éste, el presente moderno y que sólo se puede obtener cruzando el lago, flotando "entre los equilibrios contrarios". En otras palabras, es necesario unirse al agua para llegar al lugar donde no hay dolor.

El otro momento en que se menciona el Ilanto también se vincula con lo identitario, lo natural y lo infantil:

Quiero llorar diciendo mi nombre, rosa, niño y abeto a la orilla de este lago, para decir mi verdad de hombre de sangre... (vv. 36-38).

Decir el nombre es afirmar el ser, de ahí que el Ilanto se vincula con la autodefinición: Ilorar es buscar el ser. Se llora porque no se es, pero se hace para buscar el ser. Y el nombre, ese ser que se busca, esa identidad anhelada se vincula - coherentemente con lo que hemos visto- con la naturaleza, la inocencia y la infancia (rosa, niño y abeto) pero, además, con el agua pues se encuentra "a la orilla de este lago", en ese "otro lado" al que se anhela llegar, al paraíso edénico de la identidad, opuesto a la diferencia.

Ahora bien, si aceptáramos la relación entre lo líquido y el paraíso perdido, deberíamos también encontrar una relación tensa y ambigua entre odio y amor por lo líquido, tal y como existe para la Edad de Oro, bucólica e idílica. Y en efecto sucede así.

Además, de vincularse con lo deseado, la pureza y lo infantil, lo líquido se asocia a la amargura ("los densos jugos amargos", v. 2), a la destrucción y anulación del yo ("estás aquí bebiendo mi sangre", v. 10), a la enajenación del pasado y a la negación de 
la identidad ("bebiendo mi humor de niño pasado", v. 11). Como vemos, eso que es acuático y líquido también está marcado por significantes relacionados con lo trágico, por lo cual está revestido del mismo carácter que lo ambiguo de lo paradisíaco.

En relación con esto, resulta por demás interesante el verso 28: "Esos perros marinos se persiguen". Según vimos, Chevalier apunta que el perro es símbolo fundamental de la muerte, psicopompo y guardián del inframundo (1999, p. 816). Por consiguiente, al calificar a esta entidad mortal con un adjetivo que lo vincula al agua, se establece una identidad entre el agua y la muerte.

Curiosamente, el simbolismo cultural del agua se puede reducir a tres temas dominantes: fuente de vida, medio de purificación y centro de la regeneración (Chevalier, 1999, p. 52). Y, aún, cada uno de estos tres temas está vinculado con la vida o la muerte regeneradora.

Esta relación agua / muerte se cimenta también en la imagen del lago. Un lago es un recinto de agua estática, inerte y sin movimiento, razón por la cual es un lugar donde no fluye el río de Heráclito, donde el cambio no sucede. Es comprensible, entonces, que el lago sea símbolo de esa Edad de Oro donde la diferencia no existe, donde el tiempo no muta ni destruye a los humanos, donde gobierna la identidad. Pero, justamente por su carácter estático y como representación de la muerte, el agua de un lago se opone a la vida.

De ahí que podamos inferir que eso acuático es necesariamente ambiguo en el poema: por un lado, es anhelado como representación del pasado bucóli$\mathrm{Co}$, inocente, idílico; por otro, es temido como anunciador fatal e inexorable de la muerte.

Pues bien, según hemos demostrado, lo líquido se asocia con el pasado perdido del tiempo idéntico y con el futuro anhelado, mientras que lo sólido, metálico, concreto, se relaciona con el presente trágico del cambio. Pero, ¿quién es el culpable de esta tragedia, de este tiempo odiado del cambio, del cruel destino humano que aleja al hablante lírico del Edén?

\section{MISERERE \\ (QUE LA FE SE MUERE...)}

El poema se estructura siguiendo un monólogo del hablante lírico ante un interlocutor que es el destinatario lírico.

¡Ay voz antigua de mi amor!

¡Ay voz de mi verdad! (vv. 5-6).

Así, el interlocutor del hablante lírico a quien se apela con estos vocativos, es esta "voz antigua", marcada con un tiempo pasado y, por consiguiente, con todos los aspectos idílicos que hemos encontrado para este "antes", época de amor y verdad.

Era mi voz antigua

ignorante de los densos jugos amargos (vv. 1-2).

Como se puede notar, el poema se refiere a la voz antigua como una entidad separada del hablante lírico: es ella la que ignoraba la tragedia, no el Yo. Este tratamiento es consistente en el resto del texto ( $\mathrm{vv}$. 5-6, 25, 30-31). Desde esta perspectiva, "Mi voz antigua" (v. 1), no es la voz del Yo, sino que se refiere a un vínculo que tuvo el Yo con esa voz en la antigüedad: esa voz que estaba con el Yo, que lo mantenía en la inocencia. De hecho, más adelante, el poema confirma la existencia de dos voces:

¡Oh voz antigua, quema con tu lengua

esta voz de hojalata y de talco! (vv. 30-31).

En efecto, es ahora claro que la voz del yo está marcada por el presente metálico repudiado (hojalata y de talco), mientras la voz del tú es de un tiempo anterior (antigua), con la sacralidad y perfección de Dios ("voz divina", v. 24).

El uso del adjetivo "divina" asocia decididamente la voz del Tú con la imagen de Dios: la verdad es del orden de lo divino, sólo Dios es "el camino, la verdad y la vida" (Juan 14: 6, Reina Valera de 1960). Así, se trata de una imploración a Dios para que anule este tiempo moderno de tragedia y regrese al hablante lírico al tiempo de la bonanza y la perfección.

Por otra parte, la voz del hablante lírico es del presente, es una voz adolorida y quejumbrosa por sufrir en este tiempo del cambio y la decadencia, y se 
encuentra asociada con significantes propios de la figura de Cristo.

¡Ay voz de mi abierto costado... (v. 7).

Estás aquí bebiendo mi sangre... (v. 10).

El "abierto costado" es una clara referencia al momento en que Longinos de Cesarea, el soldado romano, clava su lanza en el costado de Cristo para comprobar si ha muerto (Juan, 19: 34, Reina Valera de 1960). El verso 10, "bebiendo mi sangre", establece también una relación directa con la última cena de Jesús, cuando afirma que, quien beba del vino consagrado, estará bebiendo su propia sangre (Mateo, 26: 27 y 28, Reina Valera de 1960), tradición seguida en el rito cristiano de la eucaristía. Aún podríamos aventurar que el verso 3, "lamiendo mis pies", tiene relación con el proceso de limpieza de los pies de que es objeto Cristo constantemente.

De modo que encontramos una equivalencia entre el Yo y Cristo y entre el Tú y Dios. Pero hay un matiz interesante en esta relación: no es totalmente feliz, el Cristo no está muy agradecido con el Dios. Y se lo culpa de una suerte de vampirismo divino, cuando se le acusa de estar "bebiendo mi sangre". En este orden de ideas, podríamos interpretar el verso 7 como la voz que abre el costado del Hablante Lírico. Además, es a esta voz a quien el Hablante Lírico implora que lo deje pasar al Edén ("Dejarme pasar", versos 14 y 17$)$.

Así, esta Voz Antigua/Dios es quien impide el paso a ese tiempo idílico del paraíso; es ella quien, directa o indirectamente, es culpada por abrir el costado del Hablante Lírico; es ella quien bebe la sangre del Hablante Lírico. Es por culpa de Dios que este nuevo Cristo sufre en el mundo, sin poder tener acceso al tiempo de paz e identidad del Edén perdido. El castigo humano, su tragedia, este tiempo del cambio y la decadencia, es producto de la voluntad de este Dios vampírico, de la voz antigua.

Esta visión de una figura crística reprochando a la divinidad su abandono y la tragedia humana, es común al romanticismo. Paz explica, de la siguiente forma, el hecho de que la razón crítica propia de la modernidad $-y$ que, paradójicamente, produce al romanticismo- marca un camino que lleva inexorablemente al teocidio.

Dios es lo Uno, no tolera la alteridad y la heterogeneidad sino como pecados de no ser; [pero en la modernidad] la razón tiene la tendencia a separarse de ella misma: cada vez que se examina, se escinde; cada vez que se contempla, se descubre como otra ella misma. (Paz, 1985, p. 28).

Por tal motivo, la razón del romanticismo implica, casi obligatoriamente, la crítica a la divinidad: la razón conlleva un afán de conocimiento que no comulga con los "caminos misteriosos" en que se mueve Dios. Por ello, la crisis de fe —que a menudo lleva a la muerte de Dios- es un tema romántico (Paz, 1985, p. 43).

Pero esa voz divina y antigua no responde. Ante el ruego, sólo hay silencio. Y en el poema de García Lorca, el reproche que se hace a Dios es de tal magnitud que se presenta como análogo del demonio. Dijimos que Dios, la voz antigua, es quien impide el paso al Edén (v. 14); y en el verso 17, el Hablante Lírico dice a esa voz divina: "Dejarme pasar, hombrecillo de los cuernos", con lo cual se equipara a la divinidad santa y pura con el Diablo, señor de las moscas y la tragedia. Recordemos, además, que quien prohíbe la entrada al Paraíso no es el Diablo sino Dios (Génesis, 3: 24, Reina Valera de 1960). Y, por supuesto, establecer una analogía entre ambos es blasfemo.

Así, en coincidencia con lo que afirma Octavio Paz, sobre la vinculación mística del romántico con la divinidad, "el poeta desaloja al sacerdote y la poesía se convierte en una revelación rival de la escritura religiosa" (Paz, 1985, p. 45). Aunque sea una revelación crítica de Dios.

Esta crítica a la crueldad divina por imponer sobre el ser humano semejante castigo, llega al punto de relacionar a Dios con Saturno, divinidad romana de origen griego (Cronos), famosa por devorar a sus hijos (Grimal, 1981, p. 121). El argumento subyacente a la comparación sería que Dios sacrifica al Cristo/ Ser Humano, le impone la tragedia del tiempo decadente que desemboca en la vejez y en la muerte, así como Saturno devoraba a sus hijos. 
Pocos han retratado esta escena de crueldad divina sobre los hijos del dios como el pintor español Francisco de Goya, en su pintura negra "Saturno devorando a su hijo" (Hagen y Hagen, 2003, p. 77). Se trata de un dios enloquecido que, con ojos desorbitados, devora un cadáver antropomorfo al que faltan cabeza y brazos. Esto da una idea del nivel de crueldad que se encuentra en un Dios capaz de sacrificar a su propio hijo.

La relación de Dios con Saturno llega, inclusive, más allá que sólo la destrucción de sus hijos y se vincula con su potestad sobre la Edad de Oro.

Era cuando Crono [Saturno en Roma] reinaba en el Cielo. Los hombres vivían entonces como dioses, libres de cuidado, al abrigo de las penalidades y de la miseria. No conocían la vejez... (Grimal, 1981, p. 146).

Así, el gobierno de Saturno-Cronos, por su prosperidad, es llamado la Edad de Oro (Grimal, 1981, p. 475). Y de la misma forma en que Hesíodo, en Los trabajos y los días, describe esa maravillosa época en que los hombres no caían devorados por las arenas del tiempo, es ese momento idílico y perfecto al que desea volver el hablante lírico del poema de García Lorca: un tiempo de la identidad, donde el cambio de Heráclito no domina, no corroe al ser humano con su "reloj encenizado".

Notemos que esta divinidad también posee un carácter doble: por su dominio del tiempo, también es identificado con la melancolía que produce la tragedia humana del fluir temporal: Saturno, ese cuyo gobierno es la Edad de Oro, devora a sus hijos al envejecerlos y matarlos con el tiempo.

Este carácter ambiguo que comporta Saturno/Dios, nos Ileva a un último aspecto de relevancia en el poema de García Lorca: la dualidad, el doble. Desde el título, existe una presencia importante de este tópico: "Poema doble del lago Edén". Además, el texto se estructura mediante dos voces: la voz antigua, divina, y la voz del presente de hojalata. Se presentan dos lugares: un "allí", donde todo es hermoso y perfecto, y un "acá", donde gobiernan la tragedia y la decadencia. El agua posee también un carácter dual: hay un agua de perfección y estatismo y hay otra decadente y mortal; hay un lago Edén que es, a la vez, un lago paradisíaco y un lago trágico de muerte. Hay fundamentalmente dos tiempos, un "antes", tiempo de la identidad y la completud, añorado para el futuro, y un "ahora", dominado por el cambio y la diferencia. Inclusive, la estructuración del poema en dos partes define dos poemas: toda la primera macrosecuencia marcada por la tragedia y la añoranza del pasado idílico, y la segunda, a modo de coda, donde ha cambiado todo, se vive en paz y la tragedia ha quedado en el pasado.

Este carácter doble del poema se puede explicar por la escisión que produce la razón crítica en el sujeto moderno. Retomemos la cita de Paz.

... la razón tiene la tendencia a separarse de ella misma: cada vez que se examina, se escinde; cada vez que se contempla, se descubre como otra ella misma. Si la unidad reflexiona se vuelve otra: se ve a sí misma como alteridad. Al fundirse con la razón, Occidente se condenó a ser siempre otro, a negarse a sí mismo para perpetuarse. (Paz, 1985, p. 28).

Así, mientras en el pensamiento mítico domina lo idéntico, la indiferenciación y la unicidad, la razón crítica promueve una división que atenta contra la igualdad y trata el concepto de identidad como una ilusión: en él priva el mito. "Pero yo ya no soy yo, / ni mi casa es ya mi casa" (García Lorca, 2000, p. 115). El Yo está escindido, partido por la razón, condenado eternamente a la autoespecularidad.

Sin embargo, hay un último aspecto que tomar en cuenta: el doble es una identidad entre dos yoes, una analogía entre un yo y otro yo. El doble es una analogía del yo. Esta contradicción la explica Octavio Paz cuando apunta que el romanticismo es una corriente filosófica, epistemológica y estética, fundada en la contradicción. Paradoja que reúne dos mentalidades antagónicas: modernidad y pensamiento mítico, ironía y analogía, lo grotesco y lo cósmico. Por la analogía, la poesía se convierte en mapa del universo, en mito y, como tal, busca volver a la Edad de Oro. Por la ironía, la poesía se vuelve trágica, es la disonancia en la sinfonía cósmica: la muerte (Paz, 1985, p. 52). Conciencia trágica de la contradicción humana: razón crítica y fe mística, identidad y diferencia, anhelo 
de paz que es muerte, equilibrio de contrarios, conjunción disfórica.

\section{CONCLUSIÓN ROTA (ROMANTICISMO Y VANGUARDIA)}

Decía Octavio Paz que la poesía moderna está marcada por el signo de la vanguardia, por la tradición de la ruptura. Pero, tal vez, el vínculo de las vanguardias con el romanticismo excede esa búsqueda eterna de renovación. De forma contradictoria, según apuntamos, el romanticismo busca primordialmente la afirmación del yo, la expresión de la emotividad del artista así como de su reflexión racional.

Pero, ¿acaso no es ese el mismo acicate de la vanguardia: encontrar la expresión última y lo más fidedigna posible de los procesos mentales, emotivos y psíquicos del artista? Más aún, ¿no sería ése el norte de todo arte: ser expresión del artista? ¿No es eso lo que motiva la Capilla Sixtina: la visión subjetiva de Miguel Ángel sobre la divinidad? ¿No querría Homero expresar su visión íntima sobre los dioses y los héroes griegos? ¿Altamira no será el testimonio de un cavernario que expresaba su amor personal por la cacería?

Tal vez un poco aventuradamente, podríamos pensar que el romanticismo ha existido desde siempre en el arte y que ha dominado las prácticas artísticas por encima de cualquier intento o deseo de inscripción en otras tradiciones.

Sin embargo, afirmar que todo es romántico equivaldría a afirmar que nada lo es. ¿Contradicción? Por supuesto. Ella subyace a todo lo que hace el ser humano. Toda actividad que realizamos la llevamos a cabo encegueciéndonos voluntariamente de que vamos a la muerte, de que sin importar qué tan sabio, hermoso o productivo sea lo que hagamos, igual acabaremos en el olvido, en la indiferenciación total. Absurdo fundamental del ser humano: actuamos a pesar de que vamos a desaparecer. Estas mismas páginas serán carcomidas por las cucarachas en algún anaquel perdido de la infinita biblioteca del escritor ciego. Y, sin embargo, escribo.

\section{REFERENCIAS BIBLIOGRÁFICAS}

Bajtín, M. (1989). Teoría y estética de la novela. Madrid: Taurus.

Baudes de Moresco, M. (1995). Real, simbólico, imaginario. Buenos Aires: Lugar Editorial.

Bécquer, G. A. (2003). Rimas y leyendas. México: Editores Mexicanos Unidos.

Braunstein, N. (1993). La herejía del eterno retorno. En: Coloquio. El tiempo, el psicoanálisis y los tiempos. México: Siglo XXI. 35-57.

Braunstein, N. (1985). Nada que sea más siniestro (unheimlich) que el hombre. En: A medio siglo del Malestar en la Cultura, de Sigmund Freud. (3 ${ }^{a}$ edición). México: Siglo XXI.

Buñuel, L. (1971). Un perro andaluz / La edad de oro. México: Ediciones Era. Guión de la película Un chien andalou. Producida y dirigida por Luis Buñuel. Escrita por Luis Buñuel y Salvador Dalí. París: Independiente, 1928, Blanco y negro, 17 min.

Chevalier, J. y A. Gheerbrant. (1999). Diccionario de los símbolos. (6 $6^{a}$ edición). Barcelona: Editorial Herder.

Eliade, M. (1983). Mito y realidad. Barcelona: Labor.

Freud, S. (1998). Más allá del principio del placer. En: Obras Completas. Vol. XVIII. $2^{\text {a }}$ edición. Buenos Aires: Amorrortu Editores.

García Lorca, F. (1992). Poeta en Nueva York. Madrid: Cátedra.

García Lorca, F. (2000). Romancero gitano. Madrid: Espasa Calpe.

Garcilaso de la Vega. (2004). Obra completa. Madrid: Edaf.

Grimal, P. (1981). Diccionario de mitología griega y romana. Barcelona: Paidós.

Hagen, R. y R.-M. Hagen. (2003). Goya. Barcelona: Taschen.

Paz, O. (1985). Los hijos del limo. Colombia: La oveja negra. 